\title{
The intake of high-fat diets induces an obesogenic-like gene expression profile in peripheral blood mononuclear cells, which is reverted by dieting
}

\author{
Bàrbara Reynés, Estefanía García-Ruiz, Andreu Palou* and Paula Oliver \\ Laboratory of Molecular Biology, Nutrition and Biotechnology, Universitat de les Illes Balears and CIBER de Fisiopatología de \\ la Obesidad y Nutrición (CIBERobn), E-07122 Palma de Mallorca, Spain \\ (Submitted 24 July 2015 - Final revision received 13 February 2016 - Accepted 29 February 2016 - First published online 15 April 2016)
}

\section{Abstract}

Peripheral blood mononuclear cells (PBMC) are increasingly used for nutrigenomic studies. In this study, we aimed to identify whether these cells could reflect the development of an obesogenic profile associated with the intake of high-fat (HF) diets. We analysed, by real-time RT-PCR, the dietary response of key genes related to lipid metabolism, obesity and inflammation in PBMC of control rats, rats fed a cafeteria or a commercial HF diet and rats fed a control diet after the intake of a cafeteria diet (post-cafeteria model). Cafeteria diet intake, which resulted in important overweight and related complications, altered the expressions of most of the studied genes in PBMC, evidencing the development of an obesogenic profile. Commercial HF diet, which produced metabolic alterations but in the absence of noticeably increased body weight, also altered PBMC gene expression, inducing a similar regulatory pattern as that observed for the cafeteria diet. Regulation of carnitine palmitoyltransferase I (Cpt1a) mRNA expression was of special interest; its expression reflected metabolic alterations related to the intake of both obesogenic diets (independently of increased body weight) even at an early stage as well as metabolic recovery in post-cafeteria animals. Thus, PBMC constitute an important source of biomarkers that reflect the increased adiposity and metabolic deregulation associated with the intake of HF diets. In particular, we propose an analysis of Cpt1a expression as a good biomarker to detect the early metabolic alterations caused by the consumption of hyperlipidic diets, and also as a marker of metabolic recovery associated to weight loss.

Key words: Blood cells: Biomarkers: Obesity: High-fat diets

Peripheral blood mononuclear cells (PBMC) represent a fraction of WBC composed of monocytes and lymphocytes. In addition to their role in immunity, PBMC possess specific characteristics that make them interesting biological material to be used in the search for molecular biomarkers, including early biomarkers of disease. PBMC can express a large proportion of the genome ${ }^{(1)}$ and can be easily and repeatedly collected in sufficient quantities to perform transcriptomic analysis, in contrast to the more invasive sampling of the liver, adipose tissue or the other tissues ${ }^{(2)}$. They have a fast turnover and are in continuous interaction with most parts of the body, and thus they can reflect gene expression profiles of certain pathologies and can be used for clinical diagnosis ${ }^{(3-5)}$. Moreover, PBMC can respond to hormonal changes reflecting the metabolic response of different organs, as they possess receptors for hormones such as insulin, glucagon or leptin ${ }^{(6-9)}$.

Recently, gene expression analysis in PBMC has become a key target for nutrigenomic studies. It is well known that PBMC can reflect the metabolic effect of different diets such as hyperlipidic diets on gene expression, especially on lipid and cholesterol metabolism and on inflammatory response $\mathrm{r}^{(2,10,11)}$.
These cells can also respond to specific nutrients such as PUFA, polyphenols or L-carnitine ${ }^{(12-14)}$ and to changes in feeding conditions (fasting/refeeding) ${ }^{(10,11,15,16)}$. PBMC are also good biological material to perform obesity studies. Obesity is linked to a pro-inflammatory state ${ }^{(17)}$, and in humans obesity and diabetes affect PBMC gene expression of different cytokines such as resistin, Tnf $\alpha$ and $I l-\sigma^{(18,19)}$. In addition, we have previously described in rodents that these cells reflect alterations related to diet-induced obesity, such as impairment in the response to feeding conditions, even in early stages of body weight gain $^{(10,11)}$, as well as metabolic recovery associated with weight loss based on the recovery of fasting response ${ }^{(20)}$. In fact, we have previously presented PBMC as a potential source of obesity biomarkers $^{(21)}$.

Our previous studies analysing the effect of high-fat (HF) diets on PBMC gene expression have mainly been based on the study of genes involved in lipid metabolism. In this study, we aimed to study a pool of obesity biomarkers, linked to different processes related to obesity development (lipid metabolism, obesity regulation and inflammation), which could be altered in response to the intake of HF diets since an early stage as well as

Abbreviations: Cpt1a, carnitine palmitoyltransferase I; HF, high-fat; PBMC, peripheral blood mononuclear cells; PCAF, post-cafeteria.

* Corresponding author: Professor A. Palou, fax +34971 1734 26, email andreu.palou@uib.es 
to describe their reversibility after withdrawal to a control balanced diet. Moreover, different types of HF diets were used a commercial $\mathrm{HF}$ and a cafeteria diet - inducing different degree of overweight and metabolic alterations. Description of early and flexible/reversible obesity biomarkers is extremely useful in terms of development of prevention strategies aimed at maintaining proper body weight.

\section{Methods \\ Animals, diets and experimental design}

The animal protocol followed in this study was reviewed and approved by the Bioethical Committee of the University of the Balearic Islands, following its guidelines for the use and care of laboratory animals.

We analysed gene expressions in PBMC of male Wistar rats (Charles River Laboratories España, SA) from a previous study $^{(22)}$. Male Wistar rats aged 2 months were distributed into four groups fed different diets for 4 months: a control group (control; $n$ 6) fed a control diet (with $10 \mathrm{kcal} \%$ from fat, ref. D12450B; Research Diets, Brogaarden); a HF group ( $n$ 7) fed a commercial hyperlipidic diet (with $60 \mathrm{kcal} \%$ from fat, ref. D12492; Research Diets, Brogaarden); a cafeteria group (CAF; $n$ 6) fed cafeteria diet plus control diet to ensure nutritional requirements of the animals (CAF group ingested $62 \mathrm{kcal} \%$ from fat); and a post-cafeteria group (PCAF; $n$ 6) fed for 2 months with cafeteria diet plus control diet and then for another 2 months exclusively with the control diet. The gross composition of the diets is described in Table 1. Animals were housed in pairs at $22^{\circ} \mathrm{C}$ with a $12 \mathrm{~h}$ light $-12 \mathrm{~h}$ dark cycle. Food and water were offered ad libitum and body weight was measured twice a week. At the end of the experimental period, animals were killed at the beginning of the light cycle by decapitation, and different white adipose tissue depots, both visceral (epididymal, mesenteric and retroperitoneal) and subcutaneous (inguinal), were harvested and weighed to determine adiposity.

\section{Peripheral blood mononuclear cells isolation}

From the age of 2-6 months, blood samples $(1.5-2.5 \mathrm{ml})$ were collected monthly in ad libitum-fed conditions from the saphena vein at the beginning of the light cycle (08.00-10.00 hours), using heparin in $\mathrm{NaCl}(0.9 \%)$ as anticoagulant. After blood collection, PBMC were isolated by Ficoll gradient separation, according to the instructions indicated by the manufacturer (GE Healthcare Bio Sciences), with some modifications. In brief, the anticoagulanttreated blood was diluted with an equal volume of balanced salt solution, which was prepared by mixing two stock solutions (1/10): solution A ( $5.5 \mathrm{~mm}$-anhydrous D-glucose, $5 \mathrm{~mm}-\mathrm{CaCl}_{2} .2 \mathrm{H}_{2} \mathrm{O}$,

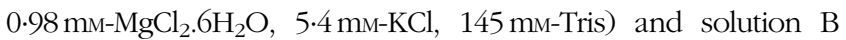
(140 mm-NaCl). Next, the blood was layered carefully over Ficoll without intermixing $(1.5 \mathrm{ml}$ of Ficoll for $2 \mathrm{ml}$ of blood mixed with balanced salt solution) in a centrifuge tub and centrifuged at $900 \mathrm{~g}$ for $40 \mathrm{~min}$ at $20^{\circ} \mathrm{C}$. PBMC, together with platelets, were harvested from the interface between Ficoll and sample layers. This layer was then centrifuged in balanced salt solution at $400 \boldsymbol{g}$ for $10 \mathrm{~min}$ at $20^{\circ} \mathrm{C}$ to wash PBMC and to remove the platelets. Every month, blood samples were collected from the saphena vein, stored at room temperature for $1 \mathrm{~h}$ and then centrifuged at $1000 \mathrm{~g}$ for $10 \mathrm{~min}$ at $4^{\circ} \mathrm{C}$ to collect the serum.

\section{Measurement of adiposity, circulating parameters and homoeostatic model assessment of insulin resistance}

Fat and lean mass were determined using an EchoMRI-700 ${ }^{\mathrm{TM}}$ (Echo Medical Systems LLC). Lipid content in the liver was determined using the Folch method ${ }^{(23)}$. Circulating levels of

Table 1. Diet composition: (a) macronutrient proportion and (b) diet fatty acid profile*

\begin{tabular}{|c|c|c|c|c|c|c|c|c|}
\hline & \multicolumn{2}{|c|}{ Control diet } & \multicolumn{2}{|c|}{ HF diet } & \multicolumn{2}{|c|}{ CAF diet } & \multicolumn{2}{|c|}{ CAF diet + control diet } \\
\hline & $\mathrm{g} \%$ & $\mathrm{kcal} \%$ & $\mathrm{~g} \%$ & $\mathrm{kcal} \%$ & $\mathrm{~g} \%$ & kcal\% & $g \%$ & $\mathrm{kcal} \%$ \\
\hline \multicolumn{9}{|c|}{ (a) Macronutrient proportion } \\
\hline Carbohydrates & $67 \cdot 3$ & 70 & $26 \cdot 3$ & 20 & $21 \cdot 3$ & 26 & $22 \cdot 5$ & 27 \\
\hline Fats & 4.3 & 10 & 34.9 & 60 & 23.2 & 64 & $22 \cdot 5$ & 62 \\
\hline Proteins & $19 \cdot 2$ & 20 & $26 \cdot 2$ & 20 & $8 \cdot 2$ & 10 & $8 \cdot 8$ & 11 \\
\hline Total & - & 100 & - & 100 & - & & - & 100 \\
\hline $\mathrm{kJ} / \mathrm{g}$ & \multicolumn{2}{|c|}{$16 \cdot 12$} & \multicolumn{2}{|c|}{21.92} & \multicolumn{2}{|c|}{13.68} & \multicolumn{2}{|c|}{$13 \cdot 68$} \\
\hline $\mathrm{kcal} / \mathrm{g}$ & \multirow{2}{*}{\multicolumn{2}{|c|}{$3 \cdot 85$}} & \multirow{2}{*}{\multicolumn{2}{|c|}{$5 \cdot 24$}} & \multicolumn{2}{|c|}{$3 \cdot 27$} & \multicolumn{2}{|c|}{3.27} \\
\hline (b) Diet fatty acid profile & & & & & & & & \\
\hline \multicolumn{9}{|l|}{ Fatty acid profile } \\
\hline SFA (\%) & \multicolumn{2}{|c|}{$25 \cdot 1$} & \multicolumn{2}{|c|}{$37 \cdot 1$} & \multicolumn{2}{|c|}{$46 \cdot 9$} & & \\
\hline MUFA (\%) & \multicolumn{2}{|c|}{$34 \cdot 7$} & \multicolumn{2}{|c|}{$46 \cdot 0$} & \multicolumn{2}{|c|}{$43 \cdot 4$} & & \\
\hline PUFA (\%) & \multicolumn{2}{|c|}{$40 \cdot 2$} & \multicolumn{2}{|c|}{$16 \cdot 9$} & \multicolumn{2}{|c|}{9.40} & & \\
\hline Linoleic:linolenic ratio & \multirow{2}{*}{\multicolumn{2}{|c|}{$6 \cdot 86$}} & \multirow{2}{*}{\multicolumn{2}{|c|}{$\begin{array}{l}7.84 \\
8.77\end{array}$}} & \multicolumn{2}{|c|}{11.7} & & \\
\hline Total $n-6: n-3$ ratio & $7 \cdot 00$ & & & & \multicolumn{2}{|c|}{4.44} & & \\
\hline
\end{tabular}

$\mathrm{HF}$, high fat; CAF, cafeteria.

${ }^{*}$ Control (D12450B) and HF (D12492) diets were from Research Diets and were purchased from Brogaarden and served as dry pellets. Cafeteria HF diet containing different foodstuffs was prepared as previously described ${ }^{(11,21)}$, and was administered while allowing free access to control diet. (a) Percentage of the macronutrients in grams and kcal as well as $\mathrm{kJ} / \mathrm{g}(\mathrm{kcal} / \mathrm{g})$ of foods of the commercial HF and the cafeteria diet; in addition, we provide macronutrient proportions ingested by the cafeteria group considering the intake of the cafeteria diet plus control diet. (b) Fatty acid profile of the diets (SFA, MUFA and PUFA) expressed as a \% of total amount of fat, linoleic:linolenic acid and total $n$ - 3 : $n-6$ dietary fatty acid ratios. Cafeteria diet composition was calculated based on the foodstuffs ingested by the animals ${ }^{(27)}$. Of note, both HF diets had similar sucrose content (approximately $9 \mathrm{~g} / 100 \mathrm{~g}$ of food). 
Table 2. Nucleotide sequences of primers and amplicon size used for real-time RT-PCR amplification

\begin{tabular}{|c|c|c|c|}
\hline Genes & Forward primer $\left(5^{\prime}-3^{\prime}\right)$ & Reverse primer $\left(5^{\prime}-3^{\prime}\right)$ & Amplicon size (bp) \\
\hline Apob48r & GGGCTACATCAGGCTTTGAG & ТТССТССССТАСААССТТСС & 150 \\
\hline Cebp $\beta$ & GAGCGACGAGTACAAGATGCGG & TTGTGCTGCGTCTCCAGGTTG & 96 \\
\hline Cpt1a & GCTCGCACATTACAAGGACAT & TGGACACCACATAGAGGCAG & 250 \\
\hline Fasn & CGGCGAGTCTATGCCACTAT & ACACAGGGACCGAGTAATGC & 222 \\
\hline $11-6$ & ATATGTTCTCAGGGAGATCTTGGAA & GTGCATCATCGCTGTTCATACA & 79 \\
\hline Slc27a2 & TTTCAGCCAGCCAGTTTTG & TCTCCTCGTAAGCCATTTCC & 157 \\
\hline Srebp1a & CCCACCCCCTTACACACC & GCCTGCGGTCTTCATTGT & 198 \\
\hline Tnfa & CCGATTTGCCATTTCATACC & TCGCTTCACAGAGCAATGAC & 237 \\
\hline Gdi1 (reference gene) & CCGCACAAGGCAAATACATC & GACTCTCTGAACCGTCATCAA & 159 \\
\hline
\end{tabular}

Apob48r, apoprotein B48 receptor; Cebp $\beta$, CCAAT/enhancer-binding protein $\beta$; Cpt1a, carnitine palmitoyltransferase I; Fasn, fatty acid synthase; S/c27a2, solute carrier family 27 member 2; Srebp1a, sterol regulatory element-binding protein 1a; Gdi1, guanosine diphosphate dissociation inhibitor 1.

glucose, leptin and TAG were measured in serum samples obtained at the end of the experimental period. Glucose concentration was measured using an Accu-Chek Glucometer (Roche Diagnostics), leptin concentration was measured using a rat leptin ELISA kit (R\&D Systems), and TAG was measured using an enzymatic colorimetric kit (Sigma Diagnostics). Homoeostatic model assessment of insulin resistance (HOMA-IR) was calculated from fasting insulin (insulin ELISA kit; Mercodia $\mathrm{AB}$ ), and glucose concentration was determined using the formula of Matthews et al. ${ }^{(24)}$ to assess insulin resistance.

\section{Total RNA isolation}

Total RNA from PBMC samples was extracted using Tripure Reagent (Roche Diagnostics) and then purified with E.Z.N.A. MicroElute RNA Clean Up (Omega Bio-tek). RNA yield was quantified in a NanoDrop ND 1000 spectrophotometer (NanoDrop Technologies), and its integrity was confirmed using agarose gel electrophoresis.

\section{Real-time RT-PCR analysis}

Real-time RT-PCR was carried out to determine mRNA expression levels of obesity-related genes in PBMC samples. Total RNA of $80 \mathrm{ng}$ was denatured at $90^{\circ} \mathrm{C}$ for $1 \mathrm{~min}$ and then reverse transcribed to complementary DNA (cDNA) using MuLV RT (Applied Biosystems) at $42^{\circ} \mathrm{C}$ for $60 \mathrm{~min}$ and a final step of $5 \mathrm{~min}$ at $99^{\circ} \mathrm{C}$ in a 2720 Thermal Cycler (Applied Biosystems). Each PCR was performed from a diluted (1/5) cDNA template, forward and reverse primers $(5 \mu \mathrm{m})$ and Power SYBER Green PCR Master Mix (Applied Biosystems) in a total volume of $11 \mu \mathrm{l}$, with the following profile: $10 \mathrm{~min}$ at $95^{\circ} \mathrm{C}$, followed by a total of forty temperature cycles $\left(15 \mathrm{~s}\right.$ at $95^{\circ} \mathrm{C}$ and $1 \mathrm{~min}$ at $60^{\circ} \mathrm{C}$ ) with a final cycle of $15 \mathrm{~s}$ at $95^{\circ} \mathrm{C}, 1 \mathrm{~min}$ at $60^{\circ} \mathrm{C}$ and $15 \mathrm{~s}$ at $95^{\circ} \mathrm{C}$. In order to verify the purity of the products, a melting curve was produced after each run according to the manufacturer's instructions. The threshold cycle $\left(C_{t}\right)$ was calculated by the instrument's software (StepOne Software version 2.0; Applied Biosystems), and the relative expression of each mRNA was calculated as a percentage of control rats, using the $2^{-\Delta \Delta C_{t}}$ method $^{(25)}$. Data were normalised against the reference gene guanosine diphosphate dissociation inhibitor 1 (Gdi1). Gdi1 was chosen based on microarray data, which showed its stability in control and diet-induced obese animals ${ }^{(16)}$.
Primers for the different genes are described in Table 2. All primers were obtained from Sigma Genosys (Sigma-Aldrich Química SA).

\section{Statistical analysis}

All data are expressed as means with their standard errors. Differences between groups were analysed using ANOVA, and least significance difference (LSD) post hoc was used when differences were statistically significant $(P<0 \cdot 05)$. The effect of fasting was analysed using Student's $t$ test. Analyses were performed with SPSS for windows (SPSS). Threshold of significance was defined at $P<0 \cdot 05$, and is indicated when different.

\section{Results and discussion}

\section{Body weight, adiposity and circulating parameters}

As we have previously described using the same set of animals $^{(22)}$, cafeteria diet intake resulted in a progressive increase in body weight: rats were $18 \%$ (1st month), $27 \%$, (2nd month), 33\% (3rd month) and $37 \%$ overweight by the end of the experimental period (4th month). This increased body weight was accompanied by progressively increased adiposity every month (27, 35, 43 and $46 \%$ of body weight as fat), with increased serum leptin levels and decreased circulating TAG due to a reduction in VLDL production rate and an increase in TAG removal from the blood ${ }^{(26)}$. These animals had drastic alterations related to the metabolic syndrome, including hyperglycaemia, insulin resistance (evidenced by increased HOMA-IR index) and increased liver lipid content (Table 3). However, animals fed a commercial HF diet presented an initial increased body weight, which was significant after the 1 st month of diet (data not shown), but was normalised thereafter, and therefore these animals did not present increased body weight at the end of the experimental period. Nevertheless, HF animals had increased adiposity throughout the experimental period (22, 28, 32 and $35 \%$ of body weight as fat after 1, 2, 3 and 4 months of dietary treatment, respectively) and metabolic alterations, although not so marked as those observed with cafeteria diet feeding. In these animals, as in cafeteria diet-fed animals, we observed increased circulating leptin, lower circulating TAG levels and increased fat deposition in the liver (Table 3). In spite of increased adiposity (because of increased 
Table 3. Characterisation of animals of the different groups (Mean values with their standard errors; $n 6-7)^{*}$

\begin{tabular}{|c|c|c|c|c|c|c|c|c|}
\hline & \multicolumn{2}{|c|}{ Control } & \multicolumn{2}{|l|}{$\mathrm{HF}$} & \multicolumn{2}{|c|}{ CAF } & \multicolumn{2}{|c|}{ PCAF } \\
\hline & Mean & SEM & Mean & SEM & Mean & SEM & Mean & SEM \\
\hline Weight $(\mathrm{g})$ & $486^{\mathrm{a}}$ & 9 & $502^{a, b}$ & 10 & $668^{\mathrm{c \Delta}}$ & 23 & $534^{\mathrm{b} \Delta}$ & 17 \\
\hline Fat mass $(\mathrm{g})$ & $110^{\mathrm{a}}$ & 7 & $177^{\mathrm{b} \Delta}$ & 10 & $296^{\mathrm{c \Delta}}$ & 24 & $142^{\mathrm{a} \Delta}$ & 13 \\
\hline Lean mass $(\mathrm{g})$ & $325^{a}$ & 5 & $260^{a}$ & 31 & $315^{a}$ & 8 & $339^{\mathrm{b} \Delta}$ & 8 \\
\hline Leptin $(\mu \mathrm{g} / \mathrm{l})$ & $14 \cdot 4^{\mathrm{a}}$ & $2 \cdot 6$ & $19.7^{\mathrm{a} \Delta}(\Delta, P=0.08)$ & 1.4 & $43 \cdot 2^{\mathrm{b} \Delta}$ & 2.5 & $12 \cdot 3^{\mathrm{a}}$ & $2 \cdot 1$ \\
\hline Glucose $(\mathrm{mmol} / \mathrm{l})$ & $6 \cdot 00$ & 0.17 & $6 \cdot 33$ & 0.22 & 6.67 & 0.11 & $6 \cdot 28$ & 0.33 \\
\hline TAG $(\mathrm{mg} / \mathrm{ml})$ & $2 \cdot 05^{\mathrm{a}}$ & 0.15 & $1.56^{\mathrm{b}}$ & 0.19 & $1.06^{\mathrm{c} \Delta}$ & $0 \cdot 11$ & $3.07^{d}$ & 0.21 \\
\hline HOMA-IR & 3.90 & 0.76 & 4.60 & 1.02 & $7.42^{\Delta}$ & 1.48 & $6 \cdot 98^{\Delta}$ & 1.07 \\
\hline Liver lipid content (mg/g tissue) & $12 \cdot 9^{\mathrm{a}}$ & 3.7 & $36 \cdot 8^{\mathrm{a} \Delta}$ & 4.5 & $101^{\mathrm{b} \Delta}$ & 24 & $24 \cdot 3^{\mathrm{a}}$ & $8 \cdot 2$ \\
\hline
\end{tabular}

HF, high fat; CAF, CAF, cafeteria; PCAF, post-cafeteria; HOMA-IR, homoeostatic model assessment of insulin resistance; LSD, least significance difference.

a,b,c,d Mean values within a row with unlike superscript letters were significantly different (one-way ANOVA, $P<0.05$ ).

${ }^{\Delta}$ Effect of different diets $v$. control diet (Student's $t$ test, $P<0.05$ or indicated when different).

* HF animals were fed a commercial HF diet and CAF animals a CAF diet plus control diet for 4 months; PCAF animals were fed a CAF diet plus control diet for 2 months and a control diet for 2 months more. LSD post hoc was used after ANOVA.

size of both visceral and subcutaneous adipose depots analysed, data not shown), animals in the commercial HF group maintained their body weight because of a decrease in lean mass, evidencing a loss in muscle mass. The more harmful effect of the cafeteria diet in comparison with the commercial HF diet seems not to be related to a different fatty acid profile or to a different sucrose content of the diets (as seen in Table 1), but rather to increased energy intake resulting from voluntary and persistent hyperphagia, which we have previously reported for highly palatable cafeteria dietary feeding ${ }^{(27)}$ in comparison with what occurred in the commercial HF group, in which we observed an increased energy intake during the 1st month, but this hyperphagia disappeared thereafter and even decreased during the last month of dietary treatment ${ }^{(22)}$. Animals in the PCAF had an important decrease in body weight and adiposity, but this was not completely reverted (Table 3). PCAF animals displayed an important improvement in their metabolic parameters, normalisation in serum leptin, glucose and TAG levels, and normalisation of liver lipid content. This experimental design is of special interest for the identification of biomarkers as we can compare the effect of two hyperlipidic diets, both causing health problems, but one of them, the commercial HF diet, was not associated with increased body weight but with increased body fat. Moreover, the post-cafeteria model gives the opportunity to analyse body weight loss and its related metabolic recovery.

\section{Regulation of mRNA expression by the intake of hyperlipidic diets in peripheral blood mononuclear cells}

To identify early markers of obesity, we screened for alterations in the expressions of a set of selected genes (involved in lipid metabolism, obesity and inflammation) in PBMC, after chronic intake of the two studied HF diets, at different times of diet exposure. Parts of the studied genes were selected on the basis of their potential usefulness according to a previous microarray analysis performed by our group in PBMC of obese animals ${ }^{(21)}$ - that is, the case of the lipid metabolism genes studied and of the obesity-related gene Slc27a2.

Lipid metabolism genes. Proper lipid metabolism regulation is crucial in order to handle the increased fat intake provided by hyperlipidic diets. Coincident to what was observed in key energy homoeostatic tissues such as adipose tissue or liver in the same animals ${ }^{(22)}$ at the end of the experimental period, the intake of the HF diets studied increased PBMC expression of a key $\beta$-oxidation gene, Cpt1a, but inhibited the expression of the lipogenic genes Srebp and Fasn (Fig. 1), reflecting a physiological adaptation to increased fat intake. For Cpt1a, a clear regulatory effect was also observed at different times of dietary treatment. Cpt1a codes for carnitine palmitoyltransferase I, an enzyme that enables the entrance of long-chain fatty acids across the inner mitochondrial membrane for subsequent $\beta$-oxidation. Its mRNA expression turned out to be of special interest to be considered as a marker of adiposity as it was equally increased as a result of the intake of both hyperlipidic diets (commercial HF and cafeteria diet) at the age of 4 months (after 2 months of diet), and this increased expression was maintained 1 month later. Unexpectedly, at the end of the experimental period, Cpt1a expression was only observed in PBMC of the cafeteria diet-fed animals, and, interestingly, altered Cpt1a expression levels were recovered in the PCAF group. We also analysed the expression of two lipogenic genes - Fasn and Srebp1a. Fasn codes for fatty acid synthase, an enzyme directly involved in fatty acid synthesis, and Srebp1a codes for a transcription factor that is critical for the expression of numerous genes involved in fatty acid synthesis. It is well described that the expressions of lipogenic genes are decreased by HF diets in order to decrease de novo lipogenesis, thereby promoting the use of fatty acids from the diet ${ }^{(28)}$. The two HF diets studied decreased Fasn and Srebp1a mRNA expressions; however, this decrease required long-term exposure, as it was not observed until the end of the experimental period (after 4 months of dietary treatment). Moreover, the expressions of these genes were not recovered after withdrawal of the 

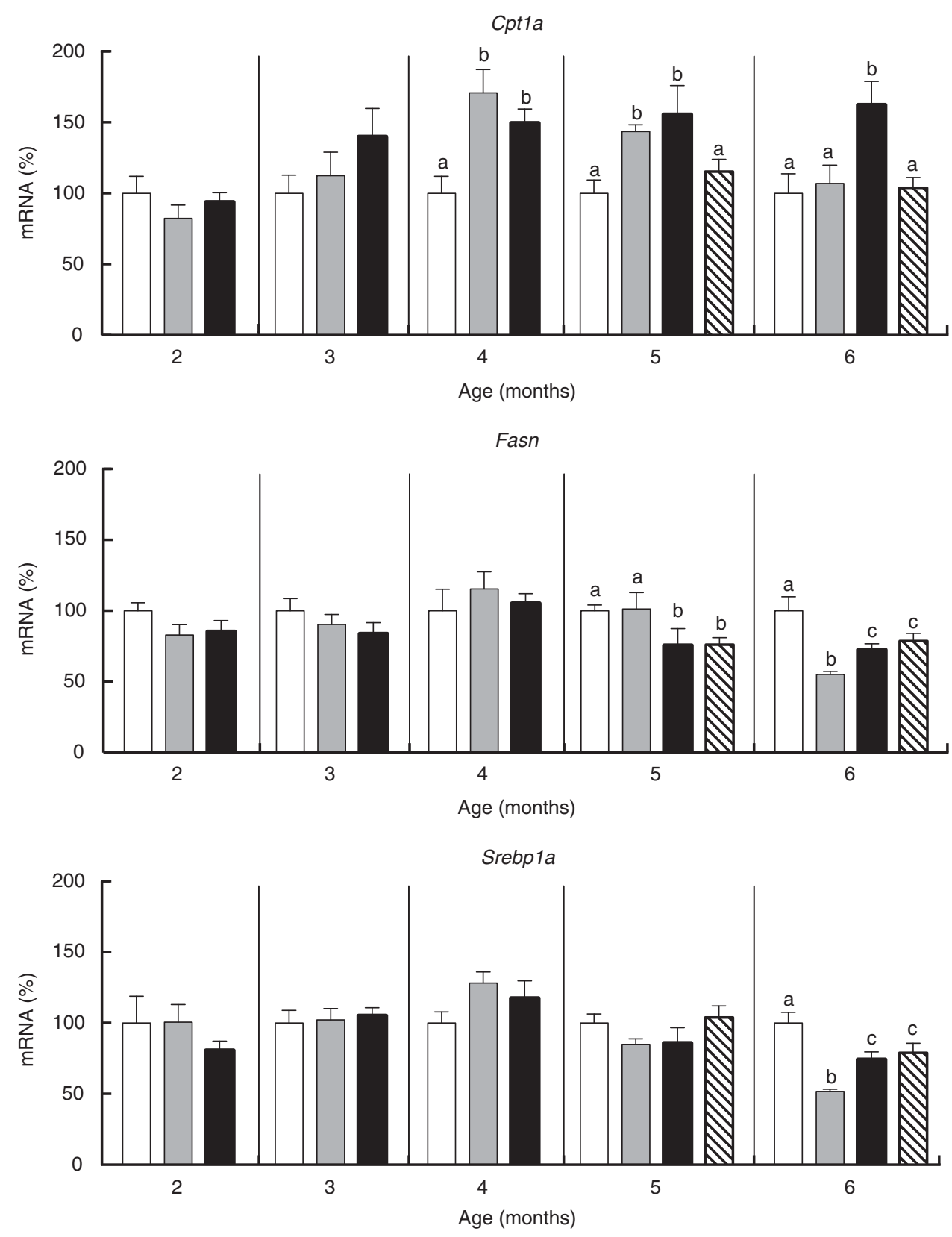

Fig. 1. Expressions of genes involved in lipid metabolism (carnitine palmitoyltransferase I (Cpt1a), fatty acid synthase (Fasn) and sterol regulatory element-binding protein 1a (Srebp1a) in peripheral blood mononuclear cells of control $(\square)$, high-fat $(\square)$, cafeteria $(\square)$ and post-cafeteria $(\mathbb{\nabla})$ animals at different ages of diet administration (from 2 to 6 months), measured by real-time RT-PCR. Values are means ( $n 6-7)$, with standard errors of ratios of specific mRNA levels relative to guanosine diphosphate dissociation inhibitor 1 , expressed as a percentage of the value of control animals that was set to $100 \%$. a,b,c Mean values with unlike letters were significantly different $(P<0.05)$. One-way ANOVA was performed for each age group. least significance difference (LSD) post hoc test was used after ANOVA.

cafeteria diet. Thus, according to our data, only Cpt1a gene expression is revealed as a potential early marker of increased adiposity and obesity-like features regardless of body weight, as animals fed a cafeteria diet presented increased body weight but not those fed a commercial HF diet, although both diets produced increased Cpt1a expression. This is of interest as the number of subjects who are not obese but present metabolic features characteristic of the obese status is increasing in our society ${ }^{(29)}$, evidencing the need for proper biomarkers for preventive strategies. In addition, Cpt1a could also be useful as a marker of metabolic recovery related to weight loss, based on the recovery of its mRNA expression in the PCAF group. In a previous study, we also reported the usefulness of Cpt1a expression in PBMC as an indicator of metabolic recovery based on recovery of its fasting response in PCAF animals in comparison with the fasting insensitivity observed in cafeteria diet-fed obese animals ${ }^{(20)}$. Thus, an analysis of Cpt1a expression levels in PBMC could serve as a sensitive indicator of metabolic risk factors directly related to lipid metabolism/ adiposity. 

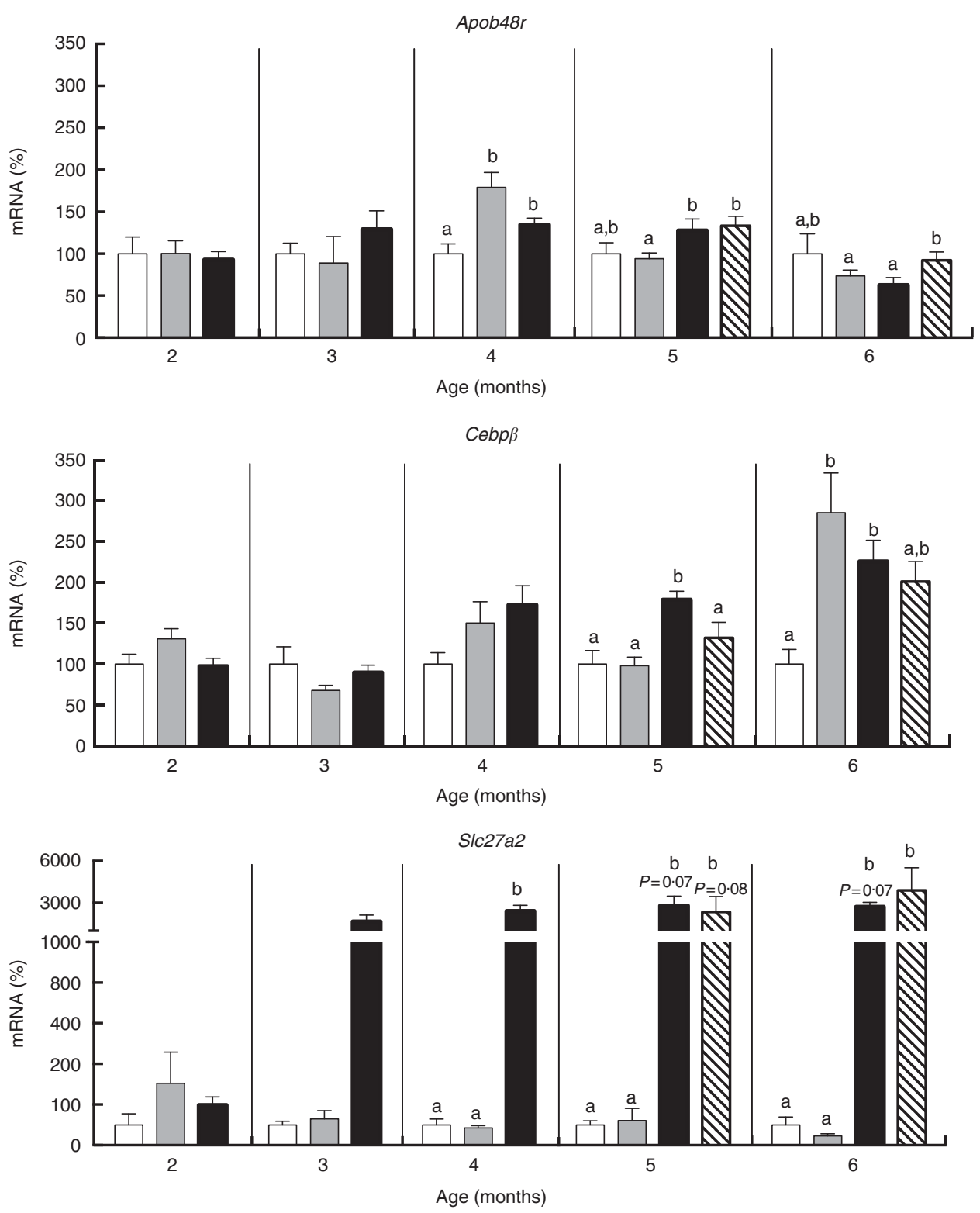

Fig. 2. Expression of obesity-related genes (apoprotein B48 receptor (Apob48r), CCAAT/enhancer-binding protein $\beta$ (Cebp $\beta$ ) and solute carrier family 27 member (SIc27a2) in peripheral blood mononuclear cells of the same animals described in Fig. 1, measured by real-time RT-PCR. Statistics: same as in Fig. 1. $\square$, Control; $\square$, high fat; $\square$, cafeteria; $\mathbb{\mathbb { Q }}$, post-cafeteria.

Obesity-related genes. There is a wide number of genes available in the literature whose altered expressions are related to obesity and are considered as obesity markers. To perform our study, we selected three obesity-related genes, which have been shown to be expressed in PBMC (Fig. 2). One of the selected genes was apoprotein $\mathrm{B} 48$ receptor (Apob48r) whose expression has been described to increase in monocytes after HF feeding, increasing lipid accumulation in these cells ${ }^{(30,31)}$. Our results show increased $A p o b 48 r$ expression in response to the two tested hyperlipidic diets after 2 months of diet exposure (4-month-old animals), but this increased expression disappeared after longer exposure to the diets. Increased Apob48r expression after a HF meal has been shown to be time-dependent: it increases in the postprandial state and is recovered thereafter ${ }^{(31)}$. On the basis of this, our results would indicate a response to the increased fat proportion of the diet after 2 months of dietary treatment, followed by an adaptation and normalisation of Apob48r expression thereafter. Another gene defined as an obesity marker is $\operatorname{Cebp} \beta$, which encodes for a CCAAT/enhancer-binding protein (C/EBP) $\beta$ transcription factor, an important regulator in controlling lipid metabolism and in the development of diet-induced obesity ${ }^{(32)}$. C/EBP $\beta$ expression has been shown to be increased in the liver, adipocytes and also in macrophages in response to HF diets, being responsible for dietary-induced inflammation in mice ${ }^{(33)}$. According to this, our results show how 3 and 4 months of cafeteria diet feeding increased PBMC Cebp $\beta$ gene expression, although mRNA returned to basal levels in the PCAF. Commercial HF diet also induced increased Cebp $\beta$ expression, but only after 4 months of diet administration. Our group has 

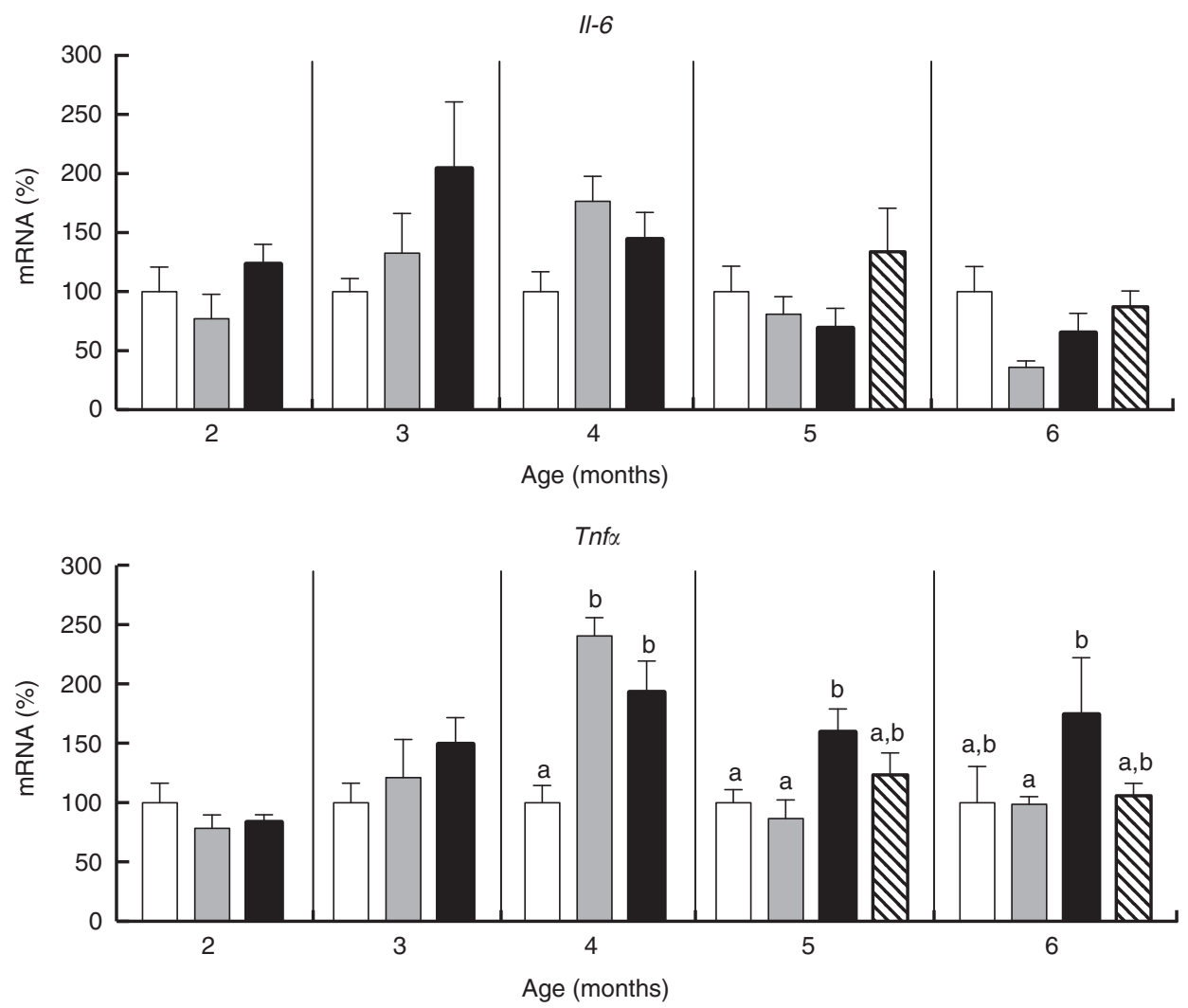

Fig. 3. Expression inflammatory genes (II-6 and Tnfa) in peripheral blood mononuclear cells of the same animals described in Fig. 1, measured by real-time RT-PCR.

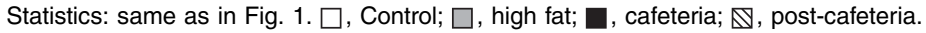

previously presented an analysis of Slc27a2 expression in PBMC as a potential overweight biomarker associated with the intake of a cafeteria diet ${ }^{(21)}$. This gene codes for solute carrier family 27 (fatty acid transporter), member 2, a free long-chain fatty acid transporter whose overexpression in the liver is related to hepatic steatosis ${ }^{(34)}$. As we observed in our previous experiment with a different set of animals ${ }^{(21)}$, Slc27a2 expression dramatically increased in PBMC of cafeteria diet-fed rats. We observed how these highly increased expression levels were present from the 1st month of dietary treatment (3-month-old animals), when animals only presented 18\% increased body weight and were maintained throughout the experimental period (when animals reached $37 \%$ overweight). On the other hand, surprisingly, no change in Slc27a2 mRNA levels was observed in animals fed a commercial HF diet, which did not develop overweight. These data suggest that increased PBMC Slc27a2 expression would be reflecting increased body weight but not the effect of the intake of a HF diet per se. However, as increased fat content in the diet produced metabolic alterations even in the absence of obesity, this gene would not be considered as a precise marker of disease or metabolic alterations as the previously mentioned Cpt1a, whose expression was altered (increased) in response to the intake of both hyperlipidic diets. Interestingly, increased Slc27a2 expression was not reverted in the PCAF group, maybe because of the fact that post-cafeteria animals still maintain a significant part of increased body weight. Further studies are required to understand the important increase in the expression of this gene, exclusively in cafeteria diet-fed animals.
Inflammatory genes. Obesity represents an expansion of adipose tissue mass characterised by a state of chronic inflammation ${ }^{(35-37)}$. Moreover, a pro-inflammatory state is positively correlated with obesity-related complications such as type 2 diabetes and $\mathrm{CVD}^{(37,38)}$. Thus, gene expression analysis of inflammatory cytokines in immune cells can be used to identify a pro-inflammatory pattern related to obesity. We have analysed the expression of two well-known pro-inflammatory markers, IL-6 and TNF $\alpha$, which are commonly involved in the aetiology of obesity (Fig. 3). There is a lot of controversy regarding $\mathrm{Il}-6$ gene expression and obesity development. Although Il-6 mRNA levels increase in adipose tissue in an obesogenic state ${ }^{(39)}$, different studies have not detected changes in $\mathrm{Il}-6$ gene expression in the liver or in blood samples of obese subjects ${ }^{(35,40)}$. Our results in PBMC at different times of the intake of HF diets did not show any conclusive evidence. Cafeteria diet feeding produced no change in $I l-6$ expression, and the same was true for the commercial HF diet, except at the end of the experimental period when Il-6 mRNA levels decreased in the HF group. As expected ${ }^{(37)}$, Tnf $\alpha$ gene expression increased in PBMC of our cafeteria-obese animals; increased expression was observed from the age of 4-6 months, and was recovered in PCAF animals. Commercial HF diet had a lower impact, and increased Tnfo expression was only observed in 4-month-old animals (after 2 months of diet). According to these results, Tnf $\alpha$ gene expression reflects increased adiposity associated with the intake of a cafeteria diet, but not that related to the commercial HF diet, which 
produces lower increased adiposity and lower metabolic complications.

\section{Conclusion}

Our results clearly indicate that PBMC gene expression can reflect the development of an obesogenic profile related to the intake of hyperlipidic diets, with alterations in selected lipid metabolism, obesity-related, and inflammatory genes. Long-term cafeteria diet intake, associated with increased body weight and important metabolic deregulations, produced a higher impact in the studied genes in comparison with a commercial HF diet, which is related to increased adiposity and metabolic complications, but not to increased body weight. Remarkably, we were able to observe a time-dependent effect on the studied biomarkers, some of them being altered at the beginning and others at the end of the dietary treatment - the latter being representative of cumulative adiposity or metabolic damage. Altogether, Cpt1a gene expression was of special interest as an early predictive biomarker of increased adiposity and metabolic damage associated with HF diet feeding, as well as of certain metabolic recovery associated with weight loss. Identification of new molecular biomarkers in blood samples is extremely useful to develop minimally invasive health preventive strategies.

\section{Acknowledgements}

CIBER de Fisiopatología de la Obesidad y Nutrición is an initiative of the ISCIII. This work was supported by the EU FP7 project BIOCLAIMS - FP7-244995. Laboratory of Molecular Biology, Nutrition and Biotechnology is a member of the European Research Network of Excellence NuGO (The European Nutrigenomics Organization, EU contract no. FOODCT-2004-506360 NUGO). E. G.-R. is recipient of a fellowship from the University of the Balearic Islands.

Author responsibilities were as follows: P. O. and A. P. designed the study; B. R. carried out the major part of the experimental work; P. O. and E. G.-R. collaborated for the animal studies; B. R., P. O. and A. P. analysed and discussed the results; $\mathrm{B}$. R. and P. O. wrote the manuscript and A. P. participated in the critical revision of the manuscript. All the authors read and approved the final version of the manuscript.

There are no conflicts of interest

\section{References}

1. Liew CC, Ma J, Tang HC, et al. (2006) The peripheral blood transcriptome dynamically reflects system wide biology: a potential diagnostic tool. J Lab Clin Med 147, 126-132.

2. de Mello VD, Kolehmanien M, Schwab U, et al. (2012) Gene expression of peripheral blood mononuclear cells as a tool in dietary intervention studies: what do we know so far? Mol Nutr Food Res 56, 1160-1172.

3. Cappuzzello C, Napolitano M, Arcelli D, et al. (2009) Gene expression profiles in peripheral blood mononuclear cells of chronic heart failure patients. Physiol Genomics 38, $233-240$.
4. Zeng XL, Zhang SY, Zheng JF, et al. (2013) Altered miR-143 and miR-150 expressions in peripheral blood mononuclear cells for diagnosis of non-small cell lung cancer. Chin Med J (Engl) 126, 4510-4516.

5. Goleva E, Jackson LP, Gleason M, et al. (2012) Usefulness of PBMCs to predict clinical response to corticosteroids in asthmatic patients. J Allergy Clin Immunol 129, 687-693.e1.

6. Powers AC, Solomon SS \& Duckworth WC (1980) Insulin degradation by mononuclear cells. Diabetes 29, 27-32.

7. Goldstein S, Blecher M, Binder R, et al. (1975) Hormone receptors, 5. Binding of glucagon and insulin to human circulating mononuclear cells in diabetes mellitus. Endocr Res Commun 2, 367-376.

8. Neal GW, Solomon SS, Shankar TP, et al. (1983) Glucagon degradation by human mononuclear cells. Diabetologia $\mathbf{2 5}$, 404-410.

9. Tsiotra PC, Pappa V, Raptis SA, et al. (2000) Expression of the long and short leptin receptor isoforms in peripheral blood mononuclear cells: implications for leptin's actions. Metabolism 49, 1537-1541.

10. Caimari A, Oliver P, Rodenburg W, et al. (2010) Feeding conditions control the expression of genes involved in sterol metabolism in peripheral blood mononuclear cells of normoweight and diet-induced (cafeteria) obese rats. $J$ Nutr Biochem 21, 1127-1133.

11. Oliver P, Reynés B, Caimari A, et al. (2013) Peripheral blood mononuclear cells: a potential source of homeostatic imbalance markers associated with obesity development. Pflugers Arch 465, 459-468.

12. Radler U, Stangl H, Lechner S, et al. (2011) A combination of $(\omega-3)$ polyunsaturated fatty acids, polyphenols and L-carnitine reduces the plasma lipid levels and increases the expression of genes involved in fatty acid oxidation in human peripheral blood mononuclear cells and HepG2 cells. Ann Nutr Metab 58, 133-140.

13. Bouwens M, van de Rest O, Dellschaft N, et al. (2009) Fish-oil supplementation induces antiinflammatory gene expression profiles in human blood mononuclear cells. Am J Clin Nutr 90, 415-424.

14. Rudkowska I, Ponton A, Jacques H, et al. (2011) Effects of a supplementation of $n$-3 polyunsaturated fatty acids with or without fish gelatin on gene expression in peripheral blood mononuclear cells in obese, insulin-resistant subjects. J Nutrigenet Nutrigenomics 4, 192-202.

15. Bouwens M, Afman LA \& Muller M (2007) Fasting induces changes in peripheral blood mononuclear cell gene expression profiles related to increases in fatty acid beta-oxidation: functional role of peroxisome proliferator activated receptor alpha in human peripheral blood mononuclear cells. Am J Clin Nutr 86, 1515-1523.

16. Caimari A, Oliver P, Keijer J, et al. (2010) Peripheral blood mononuclear cells as a model to study the response of energy homeostasis-related genes to acute changes in feeding conditions. OMICS 14, 129-141.

17. Xu H, Barnes GT, Yang Q, et al. (2003) Chronic inflammation in fat plays a crucial role in the development of obesity-related insulin resistance. J Clin Invest 112, 1821-1830.

18. Tsiotra PC, Tsigos C, Yfanti E, et al. (2007) Visfatin, TNF-alpha and IL-6 mRNA expression is increased in mononuclear cells from type 2 diabetic women. Horm Metab Res 39, 758-763.

19. Tsiotra PC, Tsigos C, Anastasiou E, et al. (2008) Peripheral mononuclear cell resistin mRNA expression is increased in type 2 diabetic women. Mediators Inflamm 2008, 892864.

20. Reynés B, Díaz-Rúa R, Cifre M, et al. (2014) Peripheral blood mononuclear cells as a potential source of biomarkers to test 
the efficacy of weight-loss strategies. Obesity (Silver Spring) 23, 28-31.

21. Caimari A, Oliver P, Rodenburg W, et al. (2010) Slc27a2 expression in peripheral blood mononuclear cells as a molecular marker for overweight development. Int $J$ Obes (Lond) 34, 831-839.

22. Reynes B, Garcia-Ruiz E, Diaz-Rua R, et al. (2014) Reversion to a control balanced diet is able to restore body weight and to recover altered metabolic parameters in adult rats long-term fed on a cafeteria diet. Food Res Int 64, 839-848.

23. Folch J, Lees M \& Sloane Stanley GH (1957) A simple method for the isolation and purification of total lipids from animal tissues. J Biol Chem 226, 497-509.

24. Matthews DR, Hosker JP, Rudenski AS, et al. (1985) Homeostasis model assessment: insulin resistance and beta-cell function from fasting plasma glucose and insulin concentrations in man. Diabetologia 28, 412-419.

25. Pfaffl MW (2001) A new mathematical model for relative quantification in real-time RT-PCR. Nucleic Acids Res 29, e45.

26. Guo J, Jou W, Gavrilova O, et al. (2009) Persistent diet-induced obesity in male $\mathrm{C} 57 \mathrm{BL} / 6$ mice resulting from temporary obesigenic diets. PLOS ONE 4, e5370.

27. Ribot J, Rodríguez AM, Rodríguez E, et al. (2008) Adiponectin and resistin response in the onset of obesity in male and female rats. Obesity (Silver Spring) 16, 723-730.

28. Horton JD \& Shimomura I (1999) Sterol regulatory elementbinding proteins: activators of cholesterol and fatty acid biosynthesis. Curr Opin Lipidol 10, 143-150.

29. Wang B, Zhuang R, Luo X, et al. (2015) Prevalence of metabolically healthy obese and metabolically obese but normal weight in adults worldwide: a meta-analysis. Horm Metab Res 47, 839-845.

30. Lumeng CN, Deyoung SM, Bodzin JL, et al. (2007) Increased inflammatory properties of adipose tissue macrophages recruited during diet-induced obesity. Diabetes 56, 16-23.

31. Varela LM, Ortega A, Bermudez B, et al. (2011) A high-fat meal promotes lipid-load and apolipoprotein B-48 receptor transcriptional activity in circulating monocytes. Am I Clin Nutr 93, 918-925.

32. Millward CA, Heaney JD, Sinasac DS, et al. (2007) Mice with a deletion in the gene for CCAAT/enhancer-binding protein beta are protected against diet-induced obesity. Diabetes $\mathbf{5 6}$, 161-167.

33. Rahman SM, Janssen RC, Choudhury M, et al. (2012) CCAAT/ enhancer-binding protein $\beta(\mathrm{C} / \mathrm{EBP} \beta)$ expression regulates dietary-induced inflammation in macrophages and adipose tissue in mice. J Biol Chem 287, 34349-34360.

34. Falcon A, Doege H, Fluitt A, et al. (2010) FATP2 is a hepatic fatty acid transporter and peroxisomal very long-chain acyl-CoA synthetase. Am J Physiol Endocrinol Metab 299, E384-393.

35. Alokail MS, Al-Daghri NM, Mohammed AK, et al. (2014) Increased TNF $\alpha$, IL-6 and ErbB2 mRNA expression in peripheral blood leukocytes from breast cancer patients. Med Oncol 31, 38.

36. Fujimoto S, Mochizuki K, Shimada M, et al. (2010) Insulin resistance induced by a high-fat diet is associated with the induction of genes related to leukocyte activation in rat peripheral leukocytes. Life Sci $\mathbf{8 7}, 679-685$.

37. Wang J, Tang H, Zhang C, et al. (2014) Modulation of gut microbiota during probiotic-mediated attenuation of metabolic syndrome in high fat diet-fed mice. ISME J 9, 1-15.

38. Kern PA, Di Gregorio GB, Lu T, et al. (2003) Adiponectin expression from human adipose tissue: relation to obesity, insulin resistance, and tumor necrosis factor-alpha expression. Diabetes 52, 1779-1785.

39. Fjeldborg K, Pedersen SB, Møller HJ, et al. (2014) Human adipose tissue macrophages are enhanced but changed to an anti-inflammatory profile in obesity. I Immunol Res $\mathbf{2 0 1 4}$ 309548.

40. Sachithanandan N, Fam BC, Fynch S, et al. (2010) Liverspecific suppressor of cytokine signaling-3 deletion in mice enhances hepatic insulin sensitivity and lipogenesis resulting in fatty liver and obesity. Hepatology 52, 1632-1642. 